\title{
Psychological Impact of various Therapeutic Modalities in Childhood Malignancy
}

\author{
Ibtessam Saad Eldin'1, Ola O Shahin², Wael S Makar', Sara H Shams Eldin ${ }^{1}$
}

${ }^{1}$ Department of Oncology and Nuclear Medicine, Faculty of Medicine, Cairo University, Egypt. ${ }^{2}$ Department of Psychiatry, Faculty of Medicine, Cairo University, Egypt.

\begin{abstract}
Background: The purpose of the study is to evaluate and compare the psychological impact of various therapeutic modalities in pediatric cancer by comparing them to healthy children across age groups. Methods: The semi-structured and the Mini International Neuropsychiatric interview (M.I.N.I Kids Test) were administered to 80 children including 40 cancer patients and 40 healthy children. Results: CNS tumors were the most common tumor $47.5 \%$ followed by heamatological malignancies $35 \%$ and Non CNS solid tumors $17.5 \%$. About two thirds of the sample reported social problems followed by school problems in $57.5 \%$ of cases. By analyzing the mood changes, there was significant depression, anxiety disorders, panic attacks and separation anxiety between the patients and the control $(\mathrm{p}=<0.001)$. The patients had also significant lack of attentionand stubbornness $(\mathrm{p}=<0.001)$. These problems did not show any difference between sex except for depression and social worries which were more in girls. These symptoms did not show any difference as regard receiving or not chemotherapy, radiotherapy or combination. Conclusion: The psychological problems were more evident in cancer patients compared to healthy children and was higher than developing countries. The present study highlighted the need of a health care team and integration of a comprehensive psychological support in the treatment plan in Egypt. This will improvequality of life and reduce the burden of treatment.
\end{abstract}

Keywords: Psychological impact- childhood cancer- cultural difference. M-I-N-I kids test

Asian Pac J Cancer Care, 4 (3), 95-100

\section{Introduction}

The overall survival of all childhood cancers have increased dramatically from the mid-1970s to reach $83 \%$ and even exceeding 90\% in certain diseases. Reducing the burden of cancer and its treatment for these children, parents, health care provider and adult survivors has become the centre of research with improvement of treatment outcome [1].

A child with cancer is exposed to a range of short and long term social, emotional and behavioral difficulties. There is a negative impact on children's social and psychological adjustment with exposure to chronic strains such as treatment related pain and visible side effects including hair loss, weight gain or loss, physical disfigurement and repeated absence from school and peers [2].

Our primary goal is to cure childhood malignancies as we are located in a developing country with limited
Submission Date: 02/07/2019 Acceptance Date: 04/02/2019

resources. This is the first study in Egypt to consider quality of life by studying the psychological impact of various therapeutic modalities in childhood cancer in an attempt to improve the outcome and limit the burden of treatment for those vulnerable patients.

\section{Materials and Methods}

\section{Patients and Method}

The study included 80 children. They were 40 cancer patients and 40 siblings who attended the pediatric oncology unit in the Kasr Al Ainy Center of Clinical Oncology and Nuclear Medicine at Cairo University from June 2012 to February 2013. The eligibility criteria included patients of both sex, age of 3-16 years with histopathological confirmation of malignancy and treated with chemotherapy, radiotherapy or a combination of these modalities. The control group consisted of 40 sibling

\section{Corresponding Author:}

Dr. Wael S Makar

Department of Oncology and Nuclear Medicine, Faculty of Medicine, Cairo University, Egypt.

Email: wael_makar@yahoo.com 
children of the study group in the same age group with no medical or mental illness. Children with history of any psychological disease before having cancer were excluded from the study. The study is a case control cross section study to evaluate the psychological impact of various therapeutic modalities in childhood malignancies.

\section{Methodology}

Analysis of the following data was done: age, sex, type of malignancy, type of treatment received (radiotherapy, chemotherapy, combined and surgery) and psycological assessment. The later was done by two interviews: The semi-structured interview and the Mini-International Neuropsychatric Interview (M.I.N.I-Kids Test). The control group was analyzed for age and sex and underwent the same psychological assessment interviews.

\section{The semi-structured interview}

This sheet starts by covering all the basic demographic data including name, age, sex, address, telephone number, scholar year (if present). It also includes the clinical data about the experience of having cancer from the start of the complaining symptoms, the investigations done, the impact of the diagnosis on the child and his family as well as on their social environment and the school.

\section{The Mini-International Neuropsychiatric Interview (M.I.N.I-Kids Test)}

It is a short structured diagnostic interview. It is developed jointly by psychiatrists and clinicians to meet the need for a short but accurate structured psychiatric interview for multicenter clinical trial, epidemiological studies and to be used as a first step in outcome tracing in clinical settings. It generates reliable and valid psychiatric diagnosis for children and adolescents [3]. The translated Arabic copy in January, 2000 done by the psychiatric department in the faculty of medicine, Ain Shams University was used in this study. It measures the mood disorders, social worries and stubbornness. The mood disorders included depression, anxiety disorders, separation, phobia, panic attacks, hallucinations, obsession and suicidal attempts.

\section{Ethical considerations}

The research protocol was accepted by both the ethical and the scientific research committees of the oncology department, Faculty of Medicine, Cairo University. The aim of the study was clarified to all the caregivers of the participants with full explanation to the method of psychometric tests applied. Participation was a free choice which did not affect the treatment plan of the patient by any means. Statistical analysis

All the data were evaluated statistically by the statistical package for the social sciences (SPSS) version 16 . The T-test was used to compare the numerical data in two different groups. Pearson correlation test was used to find correlations between numerical data of the same patient to determine the direction and significance of any correlation.

\section{Results}

A total of 40 patients were included in the study and were compared to 40 control child from the same socioeconomic environment. The mean age of the patients was 10.6 years \pm 3.4 . The boys constituted the majority $(62.5 \%)$. Most of the studied group had CNS tumors (47\%) followed by hematological malignancy (35\%) and Non-CNS solid tumors (17\%). Table 1 and 2.

The majority of the sample had significant social and school problems between the case and the control $(65 \%, 57.5 \%, p=0.001$ in both) with no economic problem difference. Table 3 . The child with cancer was subjected to rejection from some of the surrounding people thinking that cancer is a contiguous disease. He also had bad reaction from the school mates as regard alopecia and was embarrassed from the announcement of his diagnosis in the school with his disruption in school attendance because of the treatment and its complications.

As for the mood changes reported by Analysing the Mini-International Neuropsychatric Interview (M.i.n.i- kids) the cancer child suffered from mood changes elicited by significant depression, anxiety disorders, panic attacks and separation anxiety than the control group. $(\mathrm{p}=<0.001$ in all). These patients had also lack of attention with stubbornness $(\mathrm{p}=<0.001)$. These problems did not differ between both sexes except for social worries which were more in girls $(80 \%$ vs $44 \%$ for boys, $\mathrm{p}=0.046$ ). These symptoms also did not show any statistical difference as regard receiving or not chemo or radiotherapy. Table 4.

Table 1. Characteristics of the Study and the Control Group

\begin{tabular}{lccccc}
\hline & \multicolumn{2}{c}{ Patients } & \multicolumn{2}{c}{ Control } & P value \\
& \multicolumn{2}{c}{$\mathrm{N}=40$} & \multicolumn{2}{c}{$\mathrm{N}=40$} & \\
& Number & $\%$ & Number & $\%$ & \\
\hline Sex & & & & & \\
Boys & 25 & 62.5 & 28 & 70.0 & 0.2 \\
Girls & 15 & 37.5 & 12 & 30.0 & \\
Mean age & $10.6+3.4$ & \multicolumn{2}{c}{$9.7+3.0$} & 0.2 \\
\hline
\end{tabular}

Table 2. Characteristics of the 40 Patients

\begin{tabular}{lcc}
\hline Diagnosis & Frequency & Percentage \\
\hline CNS tumors & 19 & 47.5 \\
Hematological malignancy & 14 & 35.0 \\
Non-CNS Solid Tumors & 7 & 17.5 \\
Therapy & & \\
Surgery & 39 & 97.5 \\
Chemotherapy & 38 & 95.0 \\
Radiotherapy & 29 & 72.5 \\
Combined chemo -radiotherapy & 27 & 67.5 \\
\hline
\end{tabular}


Table 3. Comparative Data of the Psychological Assessment

\begin{tabular}{|c|c|c|c|c|c|}
\hline \multirow[t]{2}{*}{ Interview } & \multicolumn{2}{|c|}{ Case } & \multicolumn{2}{|c|}{ Control } & \multirow[t]{2}{*}{$P$ value } \\
\hline & No & $\%$ & No & $\%$ & \\
\hline \multicolumn{6}{|c|}{ 1) Semi-structured Interview } \\
\hline \multicolumn{6}{|c|}{ Social problems } \\
\hline$\cdot$ Yes & 23 & 57.5 & 0 & 0 & $<0.001$ \\
\hline$\cdot$ No & 17 & 42.5 & 40 & 100 & \\
\hline \multicolumn{6}{|c|}{ Economic problems } \\
\hline$\cdot$ Yes & 11 & 27.5 & 11 & 27.5 & 1 \\
\hline$\cdot$ No & 29 & 72.5 & 29 & 72.5 & \\
\hline \multicolumn{6}{|c|}{ School Problems } \\
\hline$\cdot$ Yes & 26 & 65 & 0 & 0 & $<0.001$ \\
\hline$\cdot$ No & 14 & 35 & 40 & 100 & \\
\hline \multicolumn{6}{|c|}{ 2-Mini-international Neuropsychatric Interview } \\
\hline \multicolumn{6}{|c|}{ i) Mood changes } \\
\hline \multicolumn{6}{|c|}{ Depression } \\
\hline · Yes & 16 & 40 & 0 & 0 & $<0.001$ \\
\hline$\cdot$ No & 24 & 60 & 40 & 100 & \\
\hline \multicolumn{6}{|c|}{ Suicidal attempts } \\
\hline$\cdot$ Yes & 0 & 0 & 0 & 0 & \\
\hline$\cdot$ No & 40 & 100 & 40 & 100 & \\
\hline \multicolumn{6}{|l|}{ Anxiety } \\
\hline$\cdot$ Yes & 19 & 47.5 & 0 & 0 & $<0.001$ \\
\hline$\cdot$ No & 21 & 52.2 & 40 & 100 & \\
\hline \multicolumn{6}{|c|}{ Hallucination } \\
\hline$\cdot$ Yes & 0 & 0 & 0 & 0 & \\
\hline$\cdot$ No & 40 & 100 & 40 & 100 & \\
\hline \multicolumn{6}{|c|}{ Panic attacks } \\
\hline$\cdot$ Yes & 13 & 32.5 & 0 & 0 & $<0.001$ \\
\hline$\cdot$ No & 27 & 67.5 & 40 & 100 & \\
\hline \multicolumn{6}{|c|}{ Separation anxiety } \\
\hline$\cdot$ Yes & 23 & 57.5 & 0 & 0 & $<0.001$ \\
\hline$\cdot$ No & 17 & 42.5 & 40 & 100 & \\
\hline \multicolumn{6}{|c|}{ Special phobia } \\
\hline$\cdot$ Yes & 1 & 2.5 & 0 & 0 & 1 \\
\hline$\cdot$ No & 39 & 97.5 & 40 & 100 & \\
\hline \multicolumn{6}{|l|}{ Obsession } \\
\hline$\cdot$ Yes & 0 & 0 & 0 & 0 & \\
\hline$\cdot$ No & 40 & 100 & 40 & 100 & \\
\hline \multicolumn{6}{|c|}{ ii) Social worries } \\
\hline$\cdot$ Yes & 23 & 57.5 & 0 & 0 & $<0.001$ \\
\hline$\cdot$ No & 17 & 42.5 & 40 & 100 & \\
\hline \multicolumn{6}{|c|}{ Hi-Lack of attention } \\
\hline$\cdot$ Yes & 12 & 30 & 0 & 0 & $<0.001$ \\
\hline$\cdot$ No & 28 & 70 & 40 & 100 & \\
\hline \multicolumn{6}{|c|}{ iv) Stubborness } \\
\hline$\cdot$ Yes & 18 & 45 & 0 & 0 & $<0.001$ \\
\hline$\cdot$ No & 22 & 55 & 40 & 100 & \\
\hline
\end{tabular}


Table 4. Factors Affecting Psi-Kchological Disorders

\begin{tabular}{|c|c|c|c|c|c|c|c|c|c|}
\hline \multirow[t]{4}{*}{ Symptom } & \multicolumn{2}{|c|}{ Sex } & \multirow[t]{4}{*}{$\mathrm{p}$} & \multicolumn{2}{|c|}{ Radiotherapy } & \multirow[t]{4}{*}{$\mathrm{P}$} & \multicolumn{2}{|c|}{ Chemo-Radio therapy } & \multirow[t]{4}{*}{$\mathrm{P}$} \\
\hline & Boys & Girls & & Yes & No & & Both & One & \\
\hline & $\mathrm{N}=25$ & $\mathrm{~N}=15$ & & $\mathrm{~N}=29$ & $\mathrm{~N}=11$ & & $\mathrm{~N}=27$ & $\mathrm{~N}=13$ & \\
\hline & $\mathrm{N} \%$ & $\mathrm{~N} \%$ & & $\mathrm{~N} \%$ & $\mathrm{~N} \%$ & & $\mathrm{~N} \%$ & $\mathrm{~N}, \%$ & \\
\hline \multicolumn{10}{|l|}{ Depression } \\
\hline Yes & $6(24 \%)$ & $10(66.7)$ & 0.02 & $12(41.4 \%)$ & $4(36.4 \%)$ & 1.0 & $11(40.7 \%)$ & $5(38.5 \%)$ & 1 \\
\hline No & $19(76 \%)$ & $5(33.3)$ & & $17(58.6 \%)$ & $7(63.6 \%)$ & & $16(59.3 \%)$ & $8(61.5 \%)$ & \\
\hline \multicolumn{10}{|c|}{ Suicidal attempts } \\
\hline Yes & $(\mathrm{X} 0 \%)$ & $0(0 \%)$ & & $0(0 \%)$ & $0(0 \%)$ & & $0(0 \%)$ & $0(0 \%)$ & \\
\hline No & $25(100 \%)$ & $15(100 \%)$ & & $29(100 \%)$ & $11(100 \%)$ & & $27(100 \%)$ & $13(100 \%$ & \\
\hline \multicolumn{10}{|c|}{ Mood changes } \\
\hline Yes & $14(56 \%)$ & $5(33.3 \%)$ & 0.2 & $15(51.7 \%)$ & $4(36.4 \%)$ & 0.5 & $13(48.1 \%)$ & $6(46.2 \%))$ & 1 \\
\hline No & $11(44 \%)$ & $10(66.7 \%)$ & & $14(48.3 \%)$ & $7(63.6)$ & & $14(51.9 \%)$ & $7(53.8 \%)$ & \\
\hline \multicolumn{10}{|c|}{ Hallucination } \\
\hline Yes & $0(0 \%)$ & $0(0 \%)$ & & $0(0 \%)$ & $0(0 \%)$ & & $0(0 \%)$ & $0(0 \%)$ & \\
\hline No & $25(100 \%)$ & $15(100 \%)$ & & $29(100 \%)$ & $11(100 \%)$ & & $27(100 \%)$ & $13(100 \%)$ & \\
\hline \multicolumn{10}{|c|}{ Panic attacks } \\
\hline Yes & $6(24 \%)$ & $7(46.7 \%)$ & 0.2 & $9(31 \%)$ & $4(36.4 \%)$ & 1 & $8(29.6 \%)$ & $5(38.5 \%)$ & 0.7 \\
\hline No & $19(76 \%)$ & $8(53.3 \%)$ & & $20(69 \%)$ & $7(63.6 \%)$ & & $19(70.4 \%)$ & $8(61.5 \%)$ & \\
\hline \multicolumn{10}{|c|}{ Separation anxiety } \\
\hline Yes & $12(48 \%)$ & $11(73.3 \%)$ & 0.2 & $18(62.1 \%)$ & $5(45.5 \%)$ & 0.5 & $17(63 \%)$ & $6(46.2 \%)$ & 0.5 \\
\hline No & $13(52 \%)$ & $4(26.7 \%)$ & & $11(37.9 \%)$ & $6(54.5 \%)$ & & $10(37 \%)$ & $7(53.8 \%)$ & \\
\hline \multicolumn{10}{|c|}{ Social worries } \\
\hline Yes & $11(44 \%)$ & $12(80 \%)$ & 0.046 & $17(58.6 \%)$ & $6(54.5 \%)$ & 1 & $16(59.3 \%)$ & $7(53.8 \%)$ & 1 \\
\hline No & $14(56 \%)$ & $3(20 \%)$ & & $12(41.4 \%)$ & $5(45.5 \%)$ & & $11(40.7 \%)$ & $6(46.2 \%)$ & \\
\hline \multicolumn{10}{|c|}{ Special phobia } \\
\hline Yes & $1(4 \%)$ & $0(0 \%)$ & & $1(3.4 \%)$ & $0(0 \%)$ & 1 & $1(3.7 \%)$ & $0(0 \%)$ & 1 \\
\hline No & $24(96 \%)$ & $15(100 \%)$ & & $28(96.6 \%)$ & $11(100 \%)$ & & $26(96.3 \%)$ & $13(100 \%)$ & \\
\hline \multicolumn{10}{|l|}{ Obsession } \\
\hline Yes & $0(0 \%)$ & $0(0 \%)$ & & $0(0 \%)$ & $0(0 \%)$ & & $0(0 \%)$ & $0(0 \%)$ & \\
\hline No & $25(100 \%)$ & $15(100 \%)$ & & $29(100 \%)$ & $11(100 \%)$ & & $27(100 \%)$ & $13(100 \%)$ & \\
\hline \multicolumn{10}{|c|}{ Lack of attention } \\
\hline Yes & $5(20 \%)$ & $7(46.7 \%)$ & 0.09 & $10(34.5 \%)$ & $2(18.2 \%)$ & 0.5 & $9(33.3 \%)$ & $3(23.1 \%)$ & 0.7 \\
\hline No & $20(80 \%)$ & $8(53.3 \%)$ & & $19(65.5 \%)$ & $9(81.8 \%)$ & & $18(66.7 \%)$ & $10(76.9 \%)$ & \\
\hline \multicolumn{10}{|l|}{ Stubborn } \\
\hline Yes & $10(40 \%)$ & $8(53.3 \%)$ & 0.5 & $14(48.3 \%)$ & $4(36.4 \%)$ & 0.7 & $13(48.1 \%)$ & $5(38.5 \%)$ & 0.7 \\
\hline No & $15(60 \%)$ & $7(46.7 \%)$ & & $15(51.7 \%)$ & $7(63.6 \%)$ & & $14(51.9 \%)$ & $8(61.5 \%)$ & \\
\hline
\end{tabular}

\section{Discussion}

The study is a case control cross section study aiming to evaluate psychological impact of various therapeutic options in childhood Egyptian cancer patient using the semi-structured interview and the Mini-International Neuropsychatric Interview (M.I.N.I-Kids Test). The translated Arabic copy (Jan. 2000) done by the psychiatric department in the faculty of medicine, Ain Shams University was used. The results of the present study revealed that the therapeutic modality including chemotherapy or chemo-radiotherapy in childhood malignancy did not have a significant psychological impact on the patient.
The patients in the study suffered from statistical significant social and school problems ( $p$ value $<0.001$ ) which was higher than reported in other studies [4]. This is due to the lack of a psychiatric in the multidisciplinary team and lack of school re entry programs as compared to other studies done in more developed countries [5-6]. This was comparable to another study done in Pakistan as a developing country showing marked difference between cancer patients and healthy children [7]. The patients were treated in a governmental hospital so the economic problems were not evident between the 2 groups. This is was consistent with multiple studies suggesting that youngsters with cancer under chemotherapy were at risk of two psychological difficulties mainly social 
adjustment and emotional well being $[8-9[$. Most of the patients in the present study were under 12 years and so age analysis was hard to be analysed.

These findings were due rejection from the surrounding thinking it is a contagious disease and the bad reaction from school mates as regard alopecia. The child is usually embarrassed from the announcement of his diagnosis in school and is disrupted in school attendance because of cancer therapy and related complications. Also, in Egypt there is no educational service provided to the children during their stay at home or in the hospital. This makes the school return more difficult.

The children in the studied group also showed mood disorders including depression, anxiety disorder, panic attacks, separation anxiety, lack of concentration and stubbornness with statistical significance from the control group, ( $\mathrm{p}$ value $<0.001$ ). This was higher than other studies.(10) This may be due to the high incidence of brain tumors in the study (47\%) which is considered more vulnerable to adverse psychological outcomes [11] and were usually excluded from many studies. However, other studies showed evident difference between patients and the healthy population [7-12].

Anxiety was because of frequent procedures and treatments (e.g. blood draws and intravenous [IV] placements, as well as chemotherapy). The child usually presents with anticipatory anxiety and/or nausea and vomiting. For preschool children, the worry may be about separation from a caregiver. They may demonstrate a greater resistance to being separated from parents or become more fearful of new people. They wanted to know exactly where their parents will be before, during or after treatment. Worries about pain were foremost in a child mind. Pain was controlled or eliminated whenever possible, even when this may mean a delay in a procedure.

Also in the present study, girls were affected more then boys by depression and social worries $(p=0.02$ and 0.046 ). This may be due to high vulnerability of girls to the quality of life problems [13-14]. children undergoing surgery were of better QOL than those receiving chemotherapy or radiotherapy. This could be explained by the fact that both chemotherapy and radiotherapy have many side effects that might deteriorate the children's QOL. Surgery gives the patient and his relatives the perception of nearly final cure, as compaired to other treatments such as chemotherapy and radiotherapy with their long duration as well as the possible side effects [15]. In the present study this was not obvious as all patients received post operative radiotherapy, chemotherapy or both.

Our study was limited by the small number of patients from a single center. However it is one of the pilot studies in Egypt evaluating the quality of life by studying the psychological impact of various therapeutic modalities in childhood cancer in an attempt to improve the outcome and limit the burden of treatment for those vulnerable patients.

In conclusion, comprehensive psychological support should be integrated in the treatment plan. Emphasis on the healthcare team should be done to improve the patient's quality of $>$ life and reduce the burden of treatment while respecting the cultural difference of the family. They should maintain open communication with them across the trajectory of illness whether the outcome is cure or end of life care.

\section{References}

1. American Cancer Society 2012. Cancer Facts and figures. Atlanta, Ga.

2. Barakat L.P, Kazak A.E, Gallagher P.R et al, 2000. Posttraumatic stress symptoms and stressful life events predict the long-term adjustment of survivors of childhood cancer and their mothers. Journal of Clinical Psychology in Medical Settings, 7(4), 189-196.

3. Sheehan D.V, Sheehan K.H, Shytle R.D et al., 2010. Reliability and validity of the Mini International Neuropsychiatric Interview for Children and Adolescents (MINI-KID). J Clin Psychiatry. March; 71 (3): 313-26.

4. Vance Y.H and Eiser C.2002. The school experience of the child with cancer. Child Care Health Dev; 28 (1): 5-19.

5. Searle N.S, Askins M, Bleyer W.A. 2003. home bound schooling is the least favorable option for continued education of adolescent cancer patients: a preliminary report. Med Pediatr Oncol; 40 (6): 380-4.

6. Larcombe I and Charlton A. 1996. Children's return to school after treatment for cancer: study days for teachers. J Cancer Educ; 11 (2): 102-5.

7. Chaudhry Z and Siddiqui S. 2012. Health related quality of life assessment in Pakistani paediatric cancer patients using Peds QLTM 4.0 generic core scale and PedsQL ${ }^{\mathrm{TM}}$. Cancer module. Health an Quality of life Outcomes 2012, 10: 52

8. Larcombe IJ, Walker J, Chalton A, Meller S, Jones Pm, Mott MG. 1991. Impact of childhood cancer on return to normal schooling. Br Med J. 301: 169-71. Canning EH, Hanser SB, Shade KA, Boyce WT. 1992.Mental disorders in chronically ill children: parent child discrepancy and physician identification. Pediatrics. 90: 692-71.

9. Canning EH, Hanser SB, Shade KA, Boyce WT. 1992. Mental disorders in chronically ill children: parent child discrepancy and physician identification. Pediatrics. 90: 6926.

10. Pai A.L, Drotar D, Zebracki K et al. 2006. A meta-analysis of the effects of psychological interventions in pediatric oncology on outcomes of psychological distress and adjustment. Journal of Pediatric Psychology ; 31 (9): 978988.

11. Boman K and Bodegard G. 2000. Long term coping in childhood cancer survivors: influence of illness, treatment and demographic background factors. Acta Paediatr, 89, 105-111.

12. Varni JW, Limbers CA, Burwinkle TM. 2007: Impaired Health Related Quality of Life in children andadolescents with chronic conditions: A Comparative analysis of 10 disease clusters and 33 disease categories/severities utilizing the Peds QLTM 4.0 Generic Core Scales. Health Qual Life Outcomes .5:1-15.

13. Meeske K.A, Patel S.K and Palmer S.N, 2007: Factors Associated with Health-Related Quality of Life in Pediatric Cancer Survivors. Factors Associated with Health- Related Quality of Life in Pediatric Cancer Survivors," Pediatric Blood and Cancer, Vol. 49, 2007. pp. 298-305.

14. Cantrell M. A, 2007. "Health-Related Quality of Life in Child- hood Cancer: State of the Science,"Oncology Nursing Forum, Vol. 34, No. 1, 2007, pp. 103-111. doi:10.1188/07. 
ONF.103-111.

15. Bhat SR, Goodwin TL, Burwinkle TM, Lansdale MF, Dahl GV, Huhn SL. 2005. Profile of daily life in children with brain tumors: an assessment of health related quality of life. Journal of Clinical Oncology. 23(24): 5493500.

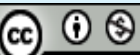

This work is licensed under a Creative Commons AttributionNon Commercial 4.0 International License. 